\title{
DIGITAL TWIN FOR CRITICAL INFRASTRUCTURES: THE VENTOTENE ISLAND PORT CASE STUDY, ITALY
}

\author{
FABRIZIO CUMO \\ CITERA Research Center University of Rome La Sapienza, Italy
}

\begin{abstract}
The digital twin has been used for decades in industries and in this last twenty years in the construction industry as a model that creates a connection between the physical systems and the digital systems. Thanks to IoT and AI, a static model evolves as a constantly updated system that is in connection with the real environment, thanks to data provided by sensors placed in it. In this paper the possibility of applying this system to complex infrastructures, such as port areas, is analysed. It has been chosen to apply it to a compact port area in order to be able to use this system, to investigate the different possibilities that it offers and to then be able to use it for larger port areas. The case study is located in the Ventotene Island, a small island located in the Tyrrhenian Sea, in front of the coast of central Italy, which is characterized by a considerable number of visitors during the summer season and a significantly reduced attendance during the rest of the year. It has been created an as-built digital model developed in BIM environment. It contains the architectural, structural and MEP models, both of port area and the building which is used for different services. Studies and simulations were carried out using the model, integrated with monitoring system to increase the security of the area. Finally, the model was connected to sensors installed in the real environment, obtaining the digital twin. Using this system, it is possible to achieve the control of facility management interventions, towards predictive maintenance, but also the control of the security and energy management, in order to verify the efficiency and the profitability of the operations and of the whole infrastructure.
\end{abstract}

Keywords: BIM environment, facility management, predictive maintenance, security management, energy management, digital twin.

\section{INTRODUCTION}

Contemporary society is witnessing the fourth industrial revolution where everything is connected: people and machines, machines with machines.

The 21 st century is characterized by an increasing interaction between the physical/real world and the virtual world. This interaction is made possible by increasing digitization and the pervasiveness of computational devices (Internet of Things - IoT) with high learning capabilities (machine learning).

Digital twins make it possible to test and understand how systems and products will behave in a wide variety of environments, using virtual space and simulation. This is done by combining different technologies into a single database that will contain all the design data for the system or product, simulation software, real-time data from the production environment and much more. The benefits are many, starting with the ability to easily access data from many different sources, to aggregate it and visualize it through a single centralized, synchronized, and shared dashboard, with the ability to add contextual information.

Digital twins can use machine learning and AI systems to process data and produce new knowledge. As evolved digital clones of the physical world, they lead to new opportunities for collaboration between product experts and data scientists whose job is to analyze data collected from a variety of sources in order to understand trends and to generate interpretative models that bring value to organizations. By standardizing data and metadata (information about data extracted from corporate knowledge, such as the position of a machine on the line and its function), other sources of information can be easily structured and linked to the 
digital twin, such as programming codes, documentation, articles, videos, or scientific projects. Ideally, a digital twin contains all the information of the physical object through a three-dimensional representation of its aspects at the mechanical level, at the geometrical level and at the electronic level, i.e., embedded software, micro software, product data, data associated with increasingly pervasive sensors and actuators. With this information, it is possible to develop an experimental activity, as in the case of product design, which saves on the creation of an expensive physical prototype, or a predictive activity, as in the case of the creation of a process, making it possible to predict anomalous behavior, risks, and errors in advance.

\section{DIGITAL TWIN, CONCEPT AND ARCHITECTURE}

The idea of accurately modelling the physical world came from National Aeronautics and Space Administration's Apollo program, to perform simulations of spacecraft from Earth [1].

DT can be defined as "a virtual mirror of the physical counterpart integrating multiple physics and scales, and it employs both dynamic sensor data and historical data from the product's life cycle". This means creating a complex virtual model that is the exact counterpart of a physical thing [2].

The concept of the digital twin was first used in 2001 by Michael Grieves, now Chief Scientist for Advanced Manufacturing at the Florida Institute of Technology, who during a Product Lifecycle Management (PLM) course at the University of Michigan described the digital twin as the virtual and digital equivalent of a physical product.

In his approach to PLM, Grieves emphasised a Mirrored Spaces Model referring to a highly dynamic representation: the real and virtual dimensions remain linked throughout the entire life cycle of the system, passing through all phases of creation, production (manufacturing), operation (support/support) and disposal. A necessary condition for the realisation of a digital twin is the existence of:

- $\quad$ physical products in real space;

- virtual products in virtual space;

- data and information flow linking systems that connect physical space to virtual space and virtual sub-spaces.

Digital twins make it possible to test and understand how systems and products will behave in a wide variety of environments, using virtual space and simulation. This is done by combining different technologies into a single database that will contain all the design data for the system or product, simulation software, real-time data from the production environment and much more. The benefits are many, starting with the ability to easily access data from many different sources, aggregate and visualise it through a single centralised, synchronised, and shared dashboard, with the ability to add contextual information [1]. Models, data, connections, and services are the core parts of the DT, even though there are various understandings of it. Said parts are introduced, respectively.

Models: The models, with the aid of the data collected by sensors, have four main functions. The first one is to produce an exact replica of the physical counterpart, including its properties, behaviour, and rules. The second one is to work in an autonomous way in the digital part, and to generate stimulated behaviours, also known as "ideal", that can be followed while operating on the physical counterpart. The third one is to predict problems that could occur to the physical object, in order to formulate preventive strategies. Lastly, the fourth one is to validate the performance or a system or product before its actual completion.

Data: It's the information provided by the data that allows the DT to perform continuously. Said data can be acquired from both digital and physical spaces, such as 
stimulated data from digital models or product lifecycle data from physical entities, and it drives the operations of the DT. For example, digital model construction, decisions in the related information systems, and operation of the entities, are all driven by data obtained from different sources. The DT works and provides further analysis and optimisation with the aid of the data, especially if it is real-time data, as it is continuously generated.

Connections: Connections allow the various entities of the DT to interact with each other, and they can be classified in connections within physical space, connections within virtual space, and connections across physical and virtual space. With the aid of said connections it's possible to interconnect physical objects for data exchange, and also to link models and information systems to obtain comprehensive information flows. The connections also allow the physical and digital components to be synchronised and consistent, in order to achieve a higher level of collaboration and optimisation.

Services: Since users may not have professional knowledge of related fields, standard services containing the DT's functions (such as prediction, evaluation, validation and optimisation) have been implemented for usage. The services are presented in their standard formats in order for them to be understandable and user-friendly. Users only need to insert parameters such as cost, time or quality to the services, to obtain the required results. The usage of the DT therefore becomes easier and more intuitive.

\section{METHODOLOGY OF APPLICATION OF DT FOR INFRASTRUCTURE}

The digital twin is a process applicable to a wide variety of human activities, both in the management of the environment in which we live and in the narrower but equally important area of industry and civil and industrial construction.

Table 1 shows the main areas of application for DT:

Table 1: Main application areas for digital twin.

\begin{tabular}{|l|l|}
\hline Areas & Topics \\
\hline Electric power generation & Smart grid planning, operation and maintenance \\
\hline Infrastructures - roads/ports/railway & $\begin{array}{l}\text { Reducing fuel consumption } \\
\text { Fault prediction and maintenance }\end{array}$ \\
\hline \multirow{2}{*}{ City management } & $\begin{array}{l}\text { Real time monitoring } \\
\text { Planning and decision-making optimization }\end{array}$ \\
\hline & $\begin{array}{l}\text { Progress monitoring } \\
\text { Work schedule and budget adjustment }\end{array}$ \\
& Resource allocation and waste tracking \\
Sonstruction & Safety monitoring for workers \\
& Quality assessment for construction \\
& Improving usage rate for equipment \\
\hline \multirow{3}{*}{ Security and Emergency } & $\begin{array}{l}\text { Mitigating existing risks or hazards } \\
\text { Security network and infrastructure protection } \\
\text { Catastrophic disaster prevention }\end{array}$ \\
\hline
\end{tabular}

By restricting the scope to the management and control of critical infrastructures, in the field of road and freight transport, such as roads, bridges, harbor quays, railway lines, etc.

The first important operation is the breakdown of the whole structure into elements, difficult because there are no manuals indicating how many pieces an infrastructure is made up of. This is why it is necessary to find the correct synthesis, so that the number of elements is neither too high nor too low. Once this is done, we start by associate the desired information 
deduced by projects, monitoring, surveys etc., and we connect it to the element and to the elementary component of the infrastructure, building an initial database that already completely digitalizes the inspection process. In fact, the inspecting technician will know exactly where the maintenance/reparation/inspection activities made by the colleague who intervened before him was located and how it was classified.

The next step is to create the Point Cloud, i.e. the digital image of a structure with a scan of the infrastructure and then the so-called image texturing, i.e. "spreading" the photographs on a georeferenced base of the infrastructure. The most interesting phase is when an element, a group of points or $\mathrm{x} \mathrm{y} \mathrm{z}$ coordinates, is related to the object and component of the bridge itself. In this way, by touching a point on the bridge, it is possible to identify the defect, which is automatically brought into the database precisely because it was previously associated with the asset element. The last step in this process is the use of artificial intelligence techniques to track the evolution of the single equipment/part of the structure by sending drones to the same point to take a picture or use satellite images in order to follow the evolution of the whole structure after a predefined period.

\section{CASE STUDY: DIGITAL TWIN OF THE PORT AREAS OF VENTOTENE}

The methodology described has been applied and verified in the port area of small island Ventotene, off the western coast of Italy, between Rome and Naples.

The main model uses are energy management [5], [6], area safety and security controls, facility management optimization and traffic pollution reduction in the dock [7].

The port area (Fig. 1(b)) is made up of a breakwater pier with a quay wall and of a square which is the main tourist and commercial docking point for ferries and hydrofoils. There is also a building, the Maritime Station which contains various services including the offices of the Port Authority, the mooring companies and the Municipality, as well as ticket offices, toilets and an infirmary.

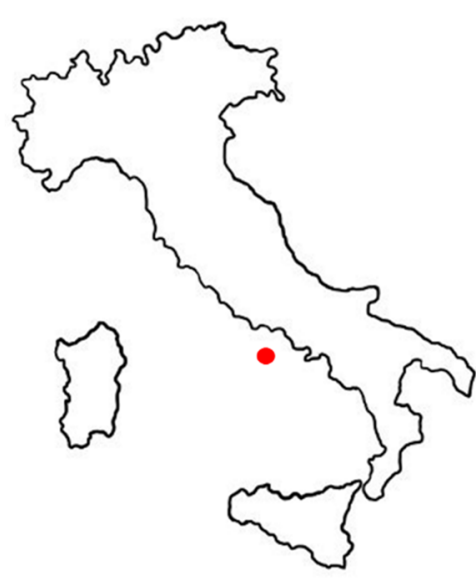

(a)

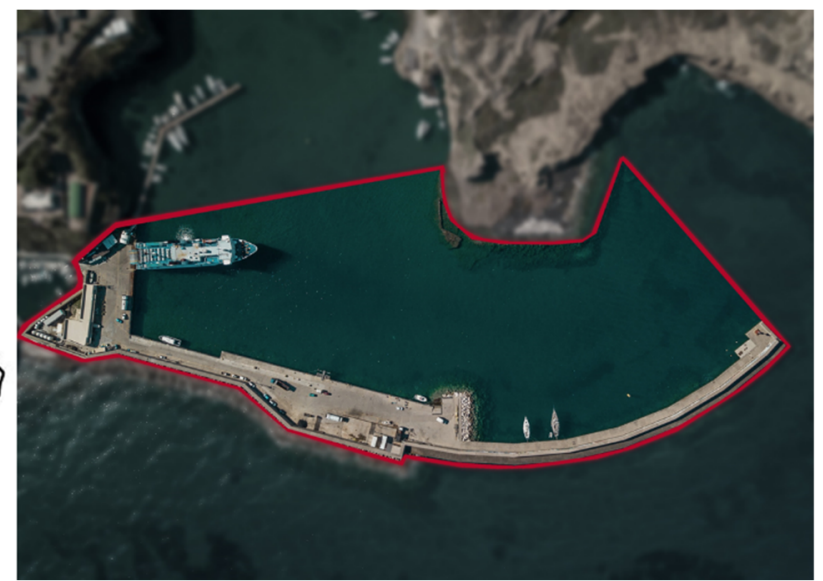

(b)

Figure 1: (a) Ventotene Island in Italy; and (b) The port area.

In order to model the Masterplan, in addition to the documentation provided by the port Authority, it was necessary to carry out surveys directly on the project area. Thanks to the surveys it has been possible to find numerous inconsistencies and missing port equipment 
that have been updated and integrated into the model. This created a valid starting point for the following phases of the project.

Loadable families have also been created and customized according to the characteristics of the objects present in the port area. In particular have been realized special equipment dedicated to the port such as anti-reflective formwork, breakwaters, different types of steel and iron plates and bollards for docking boats.

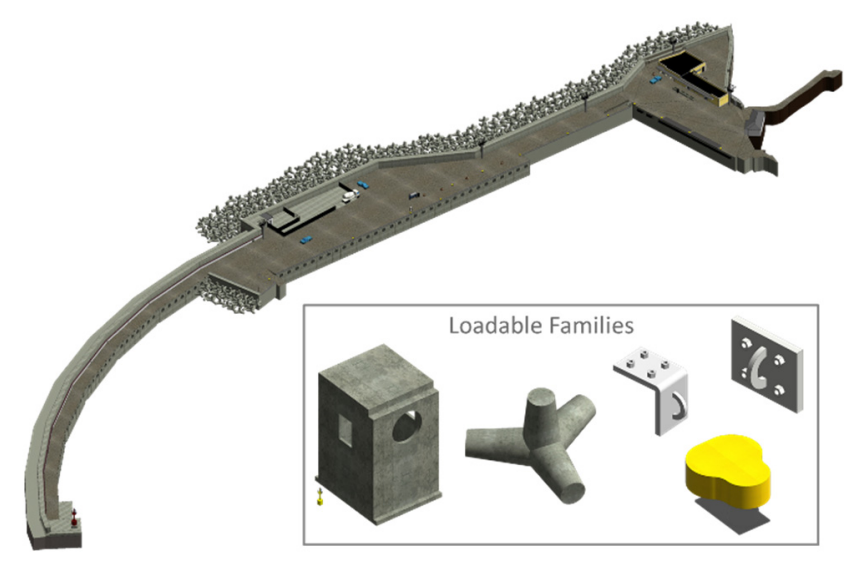

Figure 2: BIM model of the area and loadable families.

The Digital twin will be completed at the end of 2021 but the structural and technical plant [8] model has already been digitalized in BIM. This model was then imported into a GIS environment using Naviswork software [9] and studied to assess the impact on vehicular traffic (critical in the section adjacent to the Roman port) of the construction of a parking area to be used at the moment of ferry embarkation/disembarkation.

The sensor system will soon be implemented, essentially based on video cameras for image recognition, so as to be able to manage the safety and security of the area with the help of artificial intelligence systems to support the Port Authority.

\section{CONCLUSIONS}

The digitization process in the AEC sector is very important to keep the built environment efficient and safe, especially critical infrastructure such as ports.

Digital technologies can be used for different goals: increasing safety, optimizing the management of logistics, of mobility, of energy, of maintenance interventions.

Upgrading and adapting port areas according to the digitalization process allows for an improvement in the reliability of services and significant savings in management time and energetic costs [10].

The implementation of digital technologies requires specific skills from employees and managers of port areas. Promoting training in the use of these new tools is very important to ensure that the objectives of greater efficiency, quality and sustainability of port areas are achieved [11].

In fact, the enabling technologies underpinning DT are not substantially new and have gradually developed as a heterogeneous set of modelling systems: geometric and physical in its individual and various components (static, kinematic, dynamic, fluidic, electrical, 
magnetic, energy, thermal, etc.). The integrated set of all these models, plus the various modes of simulation of the individual phenomena modelled, plus the various optimization systems, all open to communication with an increasingly IOT external reality, constitutes the architecture, the substance and the disruptive potential of the Digital Twin.

The obvious advantages of using DT in critical situations are only a question of simulation response time and optimization compared to the time available to decide what to do (and not predicted in advance). But let's remember that the exponential evolution of technologies, which underpin the whole world of simulation, plays resoundingly in favor and at zero cost.

\section{ACKNOWLEDGEMENT}

The author wishes to thank prof. Sofia Agostinelli for the strong and continuous support in all Digital Twin activities of CITERA.

\section{REFERENCES}

[1] Tao, F., Liu, A. \& Hu, T., Digital Twin Driven Smart Design, Google Books edition.

[2] Batty, M., Digital twins. Environment and Planning B: Urban Analytics and City Science, 45, pp. 817-820, 2018.

[3] Centre for Digital Built Britain, 2020. https://www.cdbb.cam.ac.uk/what-we-do. Accessed: 11 Apr. 2021.

[4] Mohammadi, N. \& Taylor, J.E., Smart city digital twins. Proceedings of the 2018 IEEE Symposium Series on Computational Intelligence, SSCI 2018, pp. 1-5, 2018. DOI: 10.1109/SSCI.2017.8285439.

[5] Acciaro, M., Ghiara, H. \& Cusano, M.I., Energy management in seaports: A new role for port authorities. Energy Policy, 71, pp. 4-12, 2014.

DOI: 10.1016/j.enpol.2014.04.013.

[6] Iris, Ç. \& Lam, J.S.L., A review of energy efficiency in ports: Operational strategies, technologies and energy management systems. Renewable \& Sustainable Energy Reviews, 112, pp. 170-182, 2019. DOI: 10.1016/j.rser.2019.04.069.

[7] Acciaro M. et al., Environmental sustainability in seaports: A framework for successful innovation. Maritime Policy \& Management, 41(5), pp. 480-500, 2014. DOI: 10.1080/03088839.2014.932926.

[8] Hautala, K., Järvenpää, M.E. \& Pulkkinen, P., Digitalization transforms the construction sector throughout asset's life-cycle from design to operation and maintenance. Stahlbau, 86(4), pp. 340-345, 2017. DOI: 10.1002/stab.201710474.

[9] Coronado Mondragon, A.E., Coronado, E.S. \& Coronado Mondragon, C.E., Defining a convergence network platform framework for smart grid and intelligent transport systems. Energy, 89(2015), pp. 402-409, 2015. DOI: 10.1016/j.energy.2015.05.117.

[10] Lam, J.S.L., Ko, M.J., Sim, J.R. \& Tee, Y., Feasibility of implementing energy management system in ports. IEEE International Conference on Industrial Engineering and Engineering Management, 2017, pp. 1621-1625, 2018.

DOI: 10.1109/IEEM.2017.8290167.

[11] Woo, J.K., Moon, D.S.H. \& Lam, J.S.L., The impact of environmental policy on ports and the associated economic opportunities. Transportation Research Part A: Policy and Practice, 110, pp. 234-242, 2018. DOI: 10.1016/j.tra.2017.09.001. 